\section{Portal de periódicos eletrônicos da UFRN: Uma estratégia de divulgação da produção científica}

Maria Aniolly Queiroz Maia

Bibliotecária da Universidade Federal do Rio Grande do Norte

Resumo: O artigo contempla informações acerca do Portal de Periódicos Eletrônicos da Universidade Federal do Rio Grande do Norte (UFRN). Tratase de um estudo de natureza qualitativa, apresentando definições relacionadas à comunicação científica, periódicos científicos eletrônicos, acesso livre à informação científica e o processo de criação do Portal de Periódicos da UFRN, que faz uso do Sistema Eletrônico de Editoração de Revistas/ Open Journal Systems no gerenciamento editorial das revistas que o integram. O referido trabalho apresenta o processo de criação e relevância desse repositório digital para a comunidade científica.

Palavras-chave: Portal de Periódicos Eletrônicos da UFRN. Comunicação científica. Sistema Eletrônico de Editoração de Revistas/ Open Journal Systems.

Abstract: The article includes information about the e-journal Portal from Universidade Federal do Rio Grande do Norte (UFRN). This is a qualitative study, showing definitions related to scientific communication, electronic scientific journals, open access to scientific information and the process of creating the Portal of journals of UFRN which makes use of the Electronic Publishing System for Magazines/Open Journal Systems on the editorial management of the magazines. This work presents the process of creating and relevance of this digital repository for the scientific community.

Keywords: e-journal Portal from UFRN. Scientific communication. Electronic Publishing System for Magazines/Open Journal Systems. 


\section{Introdução}

Portal de periódicos eletrônicos dA UFRN SE refere a um repositório digital que congrega os periódicos editados na instituição. Para o gerenciamento desse ambiente, o Portal utiliza o Sistema Eletrônico de Editoração de Revistas (SEER), que é um sistema traduzido pelo Instituto Brasileiro de Informação em Ciência e Tecnologia (IBICT), a partir do Open Journal Systems (OJS).

O SEER é um sistema utilizado pela maioria dos periódicos de Instituições de Ensino Superior (IES) brasileiras, e é recomendado pela Coordenação de Aperfeiçoamento de Pessoal de Nível Superior (CAPES) na avaliação de periódicos.

Esse repositório foi criado em 2009 com a "finalidade precípua [de] integrar e disponibilizar eletronicamente o conteúdo de periódicos científicos editados na UFRN" (UNIVERSIDADE FEDERAL DO RIO GRANDE DO NORTE, 2009). Para tanto, considera-se pertinente destacar a evolução e relevância dessa base para a comunidade em geral. Nessa perspectiva, a metodologia utilizada corresponde a pesquisas bibliográficas e eletrônicas, além de uma análise qualitativa do Portal de Periódicos Eletrônicos da UFRN.

\section{Comunicação científica}

Para Leite e Costa (2007, p.92), a Comunicação Científica se refere ao "conjunto de esforços, facilidades, processos dinâmicos e complexos, consensual e socialmente compartilhados, por meio dos quais o conhecimento científico - em sua vertente tácita e explícita - é criado, compartilhado e utilizado".

Nessa perspectiva, a comunicação científica pode ser entendida como um canal no qual é possível a divulgação da ciência pelos seus pares independente de seus suportes. A mesma possui dois tipos de canais comunicacionais: o formal e o informal. O canal formal diz respeito à comunicação por meio da escrita, como é o caso dos livros, jornais, revistas, entre outros.

Para Silva (2001), os canais formais por intermédio das publicações são fundamentais para os pesquisadores, pois permitem divulgar os resultados de pesquisas, obter o reconhecimento dos pares e consequentemente ter maior visibilidade e credibilidade no meio técnico e acadêmico. O canal informal diz respeito aos contatos interpessoais, envolvendo formas públicas de informações, como conferências, 
seminários, conversas e telefonemas (MEADOWS, 1999). O canal de comunicação científica informal diz respeito ao contato face a face, ou mediados pelo computador com acesso à Internet.

Não se pode afirmar quando se deu o surgimento da pesquisa científica e consequentemente da comunicação científica (MEADOWS, 1999), todavia, sabe-se que esse processo vem sendo ampliado constantemente, principalmente após a utilização da Internet e inserção de algumas tecnologias de informação e comunicação (TICs), a saber: a criação dos periódicos científicos de acesso livre em formato eletrônico e dos Repositórios Institucionais. Essas ferramentas de divulgação da produção científica em acesso livre possibilitaram a quebra do monopólio das grandes editoras científicas, alterando consideravelmente às formas de uso, compartilhamento, disponibilização e publicação da comunicação científica, considerando que atualmente a sociedade tem acesso à informação científica de forma cada vez mais diversificada e facilitada. 


\subsection{Periódicos científicos Eletrônicos e o Acesso Livre} à Informação Científica

Operiódicocientíficoeletrônicoéaqueledisponível online, que adota padrões de cientificidade, e é de responsabilidade de instituições afins (universidades, sociedades e órgãos de pesquisa, entre outros), independentemente de possuir uma versão impressa ou não. (GRUSZYNSKI; GOLIN, 2007).

Os periódicos científicos podem ser de acesso livre ou restrito, no caso dos periódicos de acesso restrito, na maioria das vezes, são títulos de simples versões online de revistas impressas consagradas, sendo pago o acesso ao seu conteúdo e realizado por meio de assinaturas individuais ou por meio de licenças de acesso a várias opções de pacotes oferecidos pelos distribuidores e/ou editores especializados (MARDERO ARELLANO, FERREIRA, CAREGNATO, 2005). Já as revistas de acesso aberto correspondem aos títulos disponibilizados de forma livre na Internet. Essas por sua vez se desenvolveram a partir do Movimento de Acesso Livre.
O Movimento de Acesso Livre surgiu a partir de uma reunião promovida pelo Open Society Institute (OSI) em Budapeste no ano de 2001. Nesse encontro, foi desenvolvido um documento da iniciativa do movimento conhecido como Budapest Open Access Initiative (BOAI). (BAPTISTA, 2007).

O Movimento de Acesso Livre possibilitou à sociedade acesso às pesquisas científicas, sem necessidade de altos custos financeiros. Trata-se de uma iniciativa de garantia de acesso amplo e irrestrito a conteúdos disponíveis em formato digital, de modo a remover barreiras de preço e permissão, tornando a literatura científica disponível com o mínimo de restrições de uso. (SUBER, 2003).

Nesse sentido, a sociedade passou a ter acesso às publicações de periódicos e ainda às produções técnico-científicas disponibilizadas em repositórios institucionais.

\subsection{Sistema Eletrônico de Editoração de Revistas/ Open Journal Systems}

O Sistema Eletrônico de Editoração de Revistas é um software de gerenciamento de periódicos científicos, que foi traduzido no Brasil pelo Instituto Brasileiro de Informação em Ciência e Tecnologia (IBICT), a partir do Open Journal Systems (OJS), desenvolvido pelo Public Knowledge Project da Universidade British Columbia, do Canadá, através de esforços financiados pelo governo federal para 



expandir e melhorar o acesso à investigação científica. (PUBLIC KNOWLEDGE PROJECT, 2014, tradução nossa).

De acordo com Mardero Arellano (2005, p.221):

O SEER contempla ações essenciais à automação das atividades de editoração de periódicos científicos. Embora o sistema possa ser adquirido gratuitamente via Internet e seu uso ser simples, seus usuários demanda inicialmente alguma espécie de treinamento. São inúmeras possibilidades de customização do sistema e adaptação da linguagem, de acordo com as necessidades de cada periódico.

O SEER admite a participação de diferentes papeis no processo de editoração de um periódico, tais como: editor gerente, editor, editor de seção, editor de texto, editor de layout, leitor de prova, autor e leitor. Cada um destes personagens desenvolve uma determinada atividade no sistema, havendo a possibilidade de um determinado personagem efetuar mais de uma atividade, como é o caso do editor que pode desenvolver as atividades do editor de seção, editor de texto, editor de layout e leitor de prova. 
O Sistema Eletrônico de Editoração de Revista é indicado pela Coordenação de Aperfeiçoamento de Pessoal de Ensino Superior (CAPES) no que se refere à criação e gerenciamento editorial de um periódico científico em formato eletrônico. Nesse sentido, a maioria das Instituições de Ensino Superior (IES) brasileiras faz uso do referido sistema na criação dos seus periódicos.

A Universidade Federal do Rio Grande do Norte é uma das IES que passou a utilizar o SEER na criação, manutenção e publicação dos seus periódicos. Nessa perspectiva, em 2009, desenvolveu um Portal de Periódicos Eletrônicos, assunto este que será evidenciado a seguir.

\section{Portal de periódicos eletrônicos da Universidade Federal do Rio Grande do Norte}

O Portal de Periódicos Eletrônicos da Universidade Federal do Rio Grande do Norte diz respeito a um repositório digital que abriga as revistas científicas da instituição. Esse repositório digital foi criado no ano de 2009, por meio da RESOLUÇÃO 237/09 - CONSEPE

\section{(PORTAL DE PERIÓDICOS ELETRÔNICOS DA UFRN, 2016).}

O Portal da UFRN utiliza o Sistema Eletrônico de Editoração de Revistas (SEER) para o gerenciamento das publicações. Para fazer parte do portal, os editores interessados devem submeter um projeto editorial à Comissão Gestora e, em caso de parecer positivo, o editor responsável pela revista recebe treinamento para utilização do SEER. É pertinente destacar que a permanência dos periódicos no referido Portal está condicionada à implementação dos critérios mínimos exigidos na política desse repositório.

A Comissão Gestora do Portal possui representação da Biblioteca Central Zila Mamede (BCZM), Pró-Reitoria de Pós-Graduação (PPG), Pró-Reitoria de Pesquisa (PROPESQ), Editora Universitária (EDUFRN), Departamento de Ciência da Informação (DECIN) e Pró-Reitoria de Extensão (PROEX) (PORTAL DE PERIÓDICOS ELETRÔNICOS DA UFRN, 2016).

O Setor de Repositórios Digitais da BCZM é responsável pela administração desse repositório, além da realização de treinamentos e orientação no que se refere à utilização do sistema. Além do Portal de Periódicos Eletrônicos, a equipe do referido setor gerencia o Repositório Institucional, que por sua vez contempla a Biblioteca Digital de Teses e Dissertações, e a Biblioteca Digital de Monografias da Instituição. Esse setor conta com uma equipe de três profissionais 
bibliotecários, um assistente administrativo e quatro bolsistas de apoio técnico.

Atualmente o Portal de Periódicos Eletrônicos da UFRN congrega um total de vinte e nove periódicos, sendo estes: ARJ - Art Research Journal; Bagoas - Estudos gays: gêneros e sexualidades; BiblioCanto; Imburana: revista do Núcleo Câmara Cascudo de Estudos NorteRio-Grandenses; Journal of surgical and clinical research; Mneme - Revista de Humanidades; Princípios: Revista de Filosofia (UFRN); Revista ambiente; Revista Alétheia; Revista Brasileira de Inovação Tecnológica em Saúde; Revista Constituição e Garantia de Direitos; Revista Cronos; Revista de Fisioterapia Respiratória e CardioVascular; Revista de Geociências do Nordeste; Revista de Turismo Contemporâneo; Revista Direito E-nergia; Revista do GELNE; Revista Educação em Questão; Revista Extensão \& Sociedade; Revista Informação na Sociedade Contemporânea; Revista Inter-Legere; Revista Odisseia; Revista Porto; Revista PubliCa; Revista Transgressões; Saberes: Revista interdisciplinar de Filosofia e Educação; Sociedade e Território; 
Vivência: Revista de Antropologia; Revista Ciência Plural.

Vale ressaltar que os periódicos que integram o Portal estão sendo preservados pela Rede Brasileira de Preservação Digital - Cariniana, que por sua vez se refere a uma iniciativa do Instituto Brasileiro de Informação em Ciência e Tecnologia que "evidencia a possibilidade de construir e gerenciar redes de preservação digital tecnicamente sem muita complexidade e altos custos, se as instituições estão comprometidas com a salvaguarda da sua memória digital local". (MÁRDERO ARELLANO, 2012, p.85). Além disso, a equipe responsável pela manutenção do SEER atualiza periodicamente as versões do referido sistema.

\section{Considerações finais}

O crescimento de periódicos de acesso livre em formato eletrônico fez emergir a criação de softwares com padrões de qualidade para o gerenciamento editorial e posterior publicação e disseminação dos periódicos para a comunidade científica. Nesse sentido, uma das ferramentas de gerenciamento de periódicos científicos se refere ao Sistema Eletrônico de Editoração de Revista/ Open Journal Systems, recomendado pela Coordenação de Aperfeiçoamento de Pessoal de Nível Superior na avaliação da qualidade dos periódicos brasileiros.

Nessa perspectiva, muitos periódicos vinculados às Instituições de Ensino Superior (IES) brasileiras passou a utilizar o SEER no gerenciamento de seus periódicos e/ou de Portais de periódicos, como é o caso da UFRN que, em 2009, desenvolveu o Portal de Periódicos Eletrônicos da Instituição, de modo a integrar num único ambiente os periódicos da Instituição e assim garantir maior visibilidade às publicações.

Atualmente, o referido Portal contempla um total de vinte e nove periódicos, que são assessorados pela equipe do setor de Repositórios Digitais da Biblioteca Central Zila Mamede e pela Comissão Gestora do referido Portal. A despeito disso, acredita-se que ao passar dos tempos esse número cresça exponencialmente 


\section{Referência bibliográficas}

BAPTISTA, A. A. et al. Comunicação científica: o papel da Open Archives Initiative no contexto do Acesso Livre. Encontros Bibli, Florianópolis, n.esp., jan./jul. 2007.

GRUSZYNSKI, A. C.; GOLIN, C. Periódicos científicos eletrônicos e a visibilidade da ciência na web: estudo de caso na UFRGS.

DataGramaZero - Revista de Ciência da Informação, Rio de Janeiro, v.8, n.3, jun., 2007. Disponível em:

<http://www.dgz.org.br/jun07/F_I_art.htm>. Acesso em: 26 Jun. 2012.

LEITE, Fernando César Lima ; COSTA, Sely Maria de Souza Costa. Gestão do conhecimento científico: proposta de um modelo conceitual com base em processos de comunicação científica. Ciência da Informação, Brasília, v. 36, n. 1, p. 92-107, jan./abr. 2007.

MÁRDERO ARELLANO, Miguel Ángel. OJS/SEER: uma ferramenta de software livre para periódicos científicos. In: MIRANDA, Antonio; SIMEÃO, Elmira. Informação e tecnologia: conceitos e recortes. Brasilia (DF): Universidade de Brasília, 2005. p. 220-227.

Ciência da Informação. Cariniana: uma rede nacional de preservação digital. Brasília, DF, v. 41 n. 1, p.83-91, jan./abr., 2012. Disponível em: 
http://revista.ibict.br/ciinf/article/view/1354/1533. Acesso em: 10 jun. 2016.

; FERREIRA, Sueli Mara Sores Pinto; CAREGNATO, Sônia Elisa. Editoração eletrônica de revistas científicas com suporte do protocolo OAI. In: FERREIRA, Sueli Mara Soares Pinto; TARGINI, Maria das Graças. Preparação de Revistas Científicas: teoria e prática. São Paulo: Reichmann \& Autores, 2005. p. 195-229.

MEADOWS, A. J. A comunicação científica. Tradução de Antonio Agenor Briquet de Lemos. Brasília: Briquet de Lemos, 1999.

PORTAL DE PERIÓDICOS ELETRÔNICOS DA UFRN, 2016.

Disponível em< http://periodicos.ufrn.br/index/index>. Acesso em: 06 maio 2015.

PUBLIC KNOWLEDGE PROJECT, 2014. Disponível em: <https:// pkp.sfu.ca/>. Acesso em: 08 maio 2016.

SILVA, E. L. Metodologia da pesquisa e elaboração de dissertação. 3.ed. Florianópolis: Laboratório de Ensino a Distância da UFSC, 2001.

SUBER, Peter. Removing barriers to research: an introduction to open access for librarians. College and Research Libraries News, v. 64, n. 2, fev. 2003. Disponível em: 
<http://news.ala.org/ala/acrl/acrlpubs/crlnews/backissues2003/ february1/removingbarriers.htm>. Acesso em: 20 maio 2016.

\section{UNIVERSIDADE FEDERAL DO RIO GRANDE DO NORTE.}

Resolução n. 237/2009 - CONSEPE, de 15 de dezembro de

2009. Cria e regulamenta o Portal de Periódicos da Universidade

Federal do Rio Grande do Norte - UFRN. [Natal]: UFRN, 2009.

Disponível em: <http://www.bczm.ufrn.br/site/conteudo/bczm/ res2372009.pdf>. Acesso em: 10 jun. 2016. 